The National Bureau of Standards' was established by an act of Congress March 3, 1901. The Burealis overall goal is to strengthen and advance the Nation's science and technology and facilitate their effective application for public benefit. To this end, the Bureau conducts research and provides: (1) a basis for the Nation's physical measurement system, (2) scientific and technological services for industry and government. (3) a technical basis for equity in trade, and (4) technical services to promote public safety. The Bureau consists of the Institute for Basic Standards, the Institute for Materials Research, the Institute for Applied Technology, the Institute for Computer Sciences and Technology, and the Office for Information Programs.

THE INSTITUTE FOR BASIC STANDARDS provides the central basis within the United States of a complete and consistent system of physical measurement; coordinates that system with measurement systems of other nations; and furnishes essential services leading to accurate and uniform physical measurements throughout the Nation's scientific community, industry. and commerce. The Institute consists of a Center for Radiation Research, an Office of Measurement Services and the following divisions:

Applied Mathematics - Electricity - Mechanics - Heat - Optical Physics - Nuclear Sciences * - Applied Radiation * - Quantum Electronics ${ }^{3}$ — Electromagnetics ${ }^{3}$ — Time and Frequency " - Laboratory Astrophysics " - Cryogenics *.

THE INSTITUTE FOR MATERIALS RESEARCH conducts materials research leading to improved methods of measurement, standards, and data on the properties of well-characterized materials needed by industry, commerce, educational institutions, and Government; provides advisory and research services to other Government agencies; and develops, produces, and distributes standard reference materials. The Institute consists of the Office of Standard Reference Materials and the following divisions:

Analytical Chemistry - Polymers - Metallurgy - Inorganic Materials — Reactor Radiation - Physical Chemistry.

THE INSTITUTE FOR APPLIED TECHNOLOGY provides technical services to promote the use of available technology and to facilitate technological innovation in industry and Government; cooperates with public and private organizations leading to the development of technological standards (including mandatory safety standards), codes and methods of test; and provides technical advice and services to Government agencies upon requést. The Institute consists of a Center for Building Technology and the following divisions and offices:

Engineering and Product Standards - Weights and Measures - Invention and Innovation - Product Evaluation Technology - Electronic Technology - Technical Analysis - Measurement Engineering - Structures, Materials, and Life Safety " Building Environment " — Technical Evaluation and Application " — Fire Technology.

THE INSTITUTE FOR COMPUTER SCIENCES AND TECHNOLOGY conducts research and provides technical services designed to aid Government agencies in improving cost effectiveness in the conduct of their programs through the selection, acquisition, and effective utilization of automatic data processing equipment; and serves as the principal focus within the executive branch for the development of Federal standards for automatic data processing equipment, techniques, and computer languages. The Institute consists of the following divisions:

Computer Services - Systems and Software - Computer Systems Engineering — Information Technology.

THE OFFICE FOR INFORMATION PROGRAMS promotes optimum dissemination and accessibility of scientific information generated within NBS and other agencies of the Federal Government; promotes the development of the National Standard Reference Data System and a system of information analysis centers dealing with the broader aspects of the National Measurement System; provides appropriate services to ensure that the NBS staff has optimum accessibility to the scientific information of the world. The Office consists of the following organizational units:

Office of Standard Reference Data - Office of Information Activities - Office of Technical Publications - Library — Office of International Relations.

'Headquarters and Laboratories at Gaithersburg. Maryland, unless otherwise noted; mailing address Washington, D.C. 20234.

2 Part of the Center for Radiation Research.

Located at Boulder. Colorado 80302.

- Part of the Center for Building Technology. 


\section{Cost-Benefit Analysis of Computer Graphics Systems}

National Bureau of Standards

Ira W. Cotton

Computer Systems Engineering Division

Institute for Computer Sciences and Technology

National Bureau of Standards

Washington, D.C. 20234

Sponsored by the

U.S. Army Electronies Command

AMSEL-GG-OD

Fort Monmouth, N.J. 07703

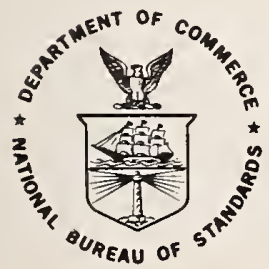

U.S. DEPARTMENT OF COMMERCE, Frederick B. Dent, Secretary

NATIONAL BUREAU OF STANDARDS, Richard W. Roberts, Director

Issued April 1974 
National Bureau of Standards Technical Note 826

Nat. Bur. Stand. (U.S.), Tech. Note 826, 47 pages (Apr. 1974)

CODEN: NBTNAE 


\section{TABLE OF CONTENTS}

1. Introduction 1

2. Computer Graphics System Design Alternatives 3

3. Analysis of System Performance 6

4. Cost Analysis 15

5. Cost-Effectiveness 18

6. Benefit Analysis 26

7. Synthesis: Cost-Benefit Analysis 30

8. Conclusions 37

Bibliography 38 

Computer Graphics Systems

$$
\text { Ira w. Cotton }
$$

This report assesses the state-of-the-art in cost-benefit analyses of computer graphics systems and suggests an approach for developing improved methodology. Cost-benefit analyses are distinguished from analyses of system performance in that the latter are directed at optimizing system performance at a given level of investment, while the former are directed at justifying the investment itself.

Computer graphic system design alternatives are first outlined. Then methods of analyzing the performance and costs of computer systems in general and graphic systems in particular are discussed. With this information it is shown how cost-effectiveness analyses may be performed. The next crucial step is to conduct benefit analysis, an ill-defined art. The results of benefit analysis must be combined with cost-effectiveness analysis in order to perform the desired cost-benefit analysis.

An experimental methodology is suggested for better performing benefit analyses of computer graphics systems. A more rigorous formulation of the cost-benefit procedure is then outlined. No attempt is made in this report to actually perform such an analysis.

Key words: Computer graphics, cost-benefit analysis, cost-effectiveness, economics, performance evaluation

1. Introduction

Computer graphics is a sub-discipline within computer science which deals with the manipulation of digital representations of pictorial information, including output of the picture on an appropriate display device and modification of the image in response to operator-initiated 
actions. There are many systems based on this technology in use today, primarily in the area of computer-aided design, and many cost savings are attributed to such systems. Hard evidence to support such claims is mostly lacking, however.

Few studies have been published relating economic principles to the design and implementation of computer graphics systems. Those that have been published deal with only one side of what is essentially a two-faceted problem. Either a detailed analysis of the costs and performance of an optimized system is presented, without corresponding analysis of the economic benefits to be derived; or expected benefits are estimated without discussion of the costs of a system to achieve those savings. The first type of study may be characterized as a cost-effectiveness evaluation; the second as a benefit analysis.

Cost-effectiveness studies are aimed at optimizing the performance of a system according to stated criteria and for a given level of investment. The sensitivity of system performance to changes in level of investment may also be considered within the scope of cost-effectiveness analysis. No value, however, is assigned to the benefits from improved performance. Benefit analysis, on the other hand, investigates just this issue, the value of improved performance, but without regard to the cost of achieving it.

Cost-benefit analysis provides a link between cost-effectiveness analysis and benefit analysis. Cost-benefit analysis is concerned with providing adequate information for making the investment decision. Is the stream of benefits resulting from the use of a system with a given level of performance greater than the required investment? What is the optimal level of investment to maximize net benefit? Such are the questions addressed by cost-benefit analysis.

Cost-effectiveness analysis is necessary but not sufficient for cost-benefit analysis. A valid cost-benefit study requires that the optimal level of performance for a given level of investment be considered. Alternatively stated, for each given level of investment, the value of the benefits considered should be the maximum possible. This is precisely the information provided by cost-effectiveness studies. What cost-effectiveness studies fail to provide is any assessment of the value of the benefits. Such assessments are often difficult to perform, but they are crucial to the investment decision.

We will be concerned in this report with the methodology 
of cost-benefit analysis. Methodologies for cost-effectiveness studies will be considered too because, as has just been explained, they are essential for valid cost-benefit studies. The relevant literature will be critically reviewed and suggestions offered where published accounts are lacking. No attempt is made here to actually perform such an analysis.

\section{Computer Graphics System Design Alternatives}

Before any consideration of economic analysis is possible it is first necessary to outline the technology of the systems under consideration: It is convenient to assign graphic systems to one of three main classes, as follows.

\section{Basic System}

Computer graphics systems of the type under analysis consist, in their simplest form, of an analog display device similar to an oscilloscope, a display processing unit which converts digital display commands to analog signals to drive the display, and a general purpose computer system which generated the digital commands in accordance with some application program. This system is illustrated in Figure 1.

\section{Satellite System}

This basic system may grow in a number of ways [22]. More and more features may be added to the display processor until it comes to resemble a computer itself. This permits the display device to be located remotely from the main computer, connected by a communications link. Since the link is generally slower than the processing rate of the display, local storage is required to hold the commands sent from the central computer. However, in this type of a system we permit only primary storage; secondary or mass storage such as a disk or drum is not permitted. This type of configuration is called a satellite graphics system because the graphics processor is located at a distance from the central computer but is dependent on it. The general configuration is illustrated in Figure 2 .

Such a system offers a number of tradeoffs for the designer [25]. The speed of the communications link, the power of the display processor and the amount of local 


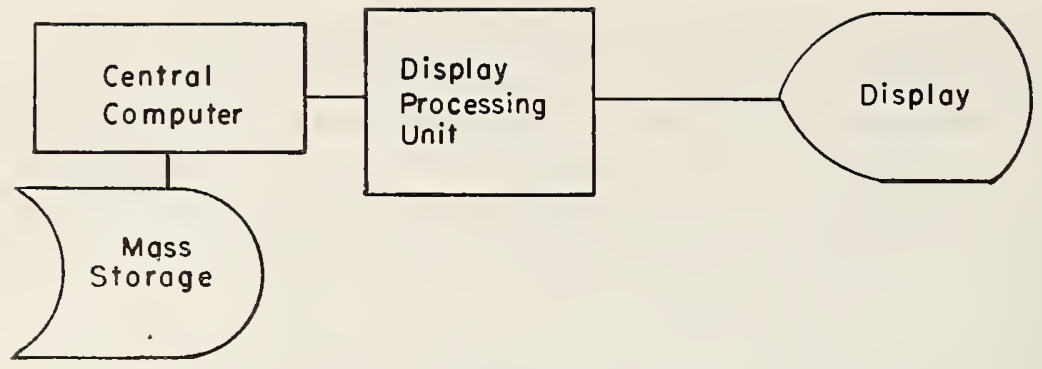

Figure 1. Basic Computer Graphics System

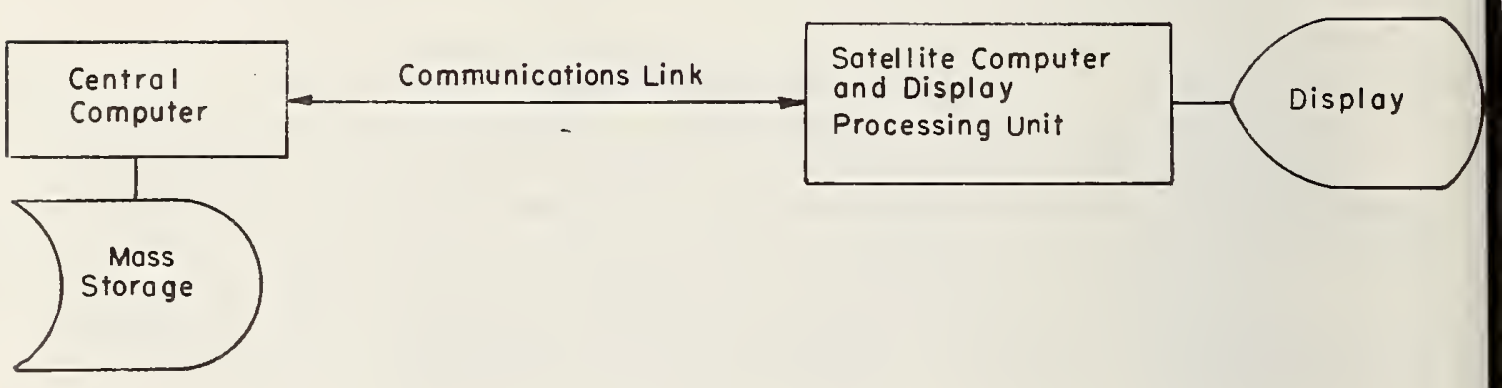

Figure 2. Satellite Computer Graphics System

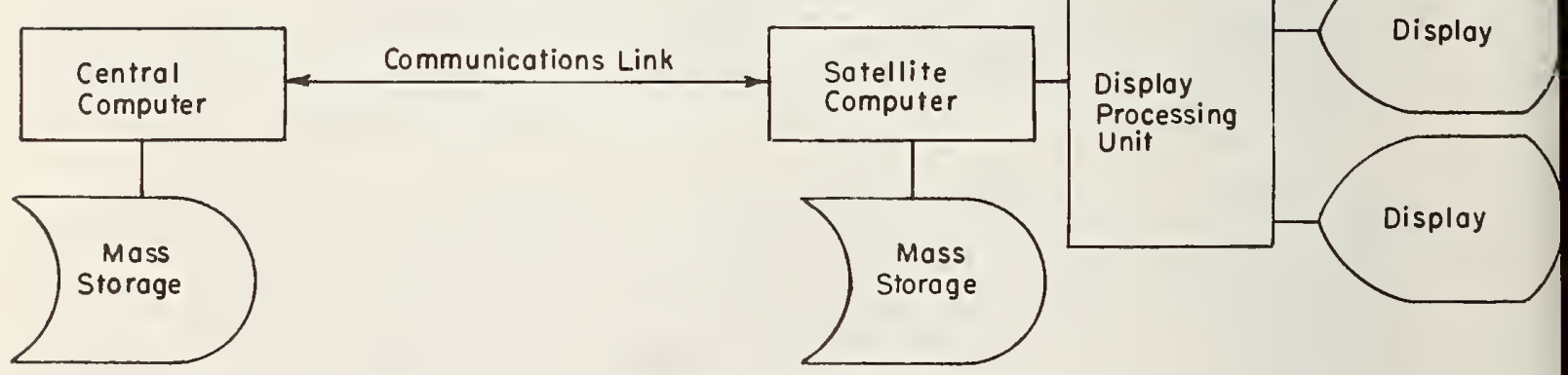

Figure 3. Network Graphics Configuration 
primary storage all may be increased at increased cost. Also, certain tasks may be performed either in the main computer or in the local processor. The decision as to which components to upgrade and where to perform processing tasks is not obvious.

\section{Network Configuration}

The situation can get even more complex. It is well within the capability of today's minicomputers to control multiple displays located remotely from the central computer. In such configurations, it is again desirable to separate the digital processing functions from the analog conversion. In addition, it will probably be necessary at this stage to permit the graphics processor to have a mass storage subsystem. All of this results in a true network configuration where multiple users share facilities at each end of the communications link. This is illustrated in Figure 3.

The attachment of input devices has not been considered in order to simplify the problem. In general, innut revices send their data to the closest processor. In the first case this would be the main computer. In the latter two cases input signals would be initially processed by the satellite computer. The degree of processing performed at the satellite in response to inputs, however, is a design variable and may vary widely from system to system [7].

\section{Tradeoffs}

For each of these types of systems there are three types of tradeoffs which can be made: hardware/hardware, hardware/software and software/software. Hardware/hardware. tradeoffs refer to the possibility of diverting costs from one component to upgrade another. For example, mass storage capacity at a satellite might be reduced in order to pay for a faster data link, or vice versa. Hardware/software tradeoffs refer to the possibility of implementing certain functions either in hardware or software. Character generation is a good example of a function which can be provided either way. Software/software tradeoffs refer to the possibility of performing certain processing tasks either in the main computer or the satellite. Display generation, or the process of formatting display commands from a description of the graphic design in a data structure, is an example of a function which may be performed in either place. All of these types of tradeoffs 
challenge the system designer to come up with the optimum for a particular set of criteria. This is what the art of system design is all about, and efforts to express these tradeoffs analytically is what is meant by making system design into a science.

\section{Analysis of System Performance}

There are essentially two basic approaches to evaluating the performance of a computer system: observation and analysis [30]. The system is either set various tasks (benchmarks) to perform and is graded on how well it performs them; or the system is analyzed in terms of specific parameters in order to derive a measure of performance. The tradeoff between these two approaches is between the detail and accuracy of the analysis and the cost of performing it. The first method has the appeal of direct measurement: the system is assessed as a whole. However, benchmarks are expensive to prepare and to run. Parametric analyses are less expensive to perform, but their results are less reliable since the effects of small errors in determining the parameters may be cumulative. Specific techniques of system analysis fall somewhere on a continum between pure observation and pure parametric evaluation.

\section{Feature Analysis}

The first serious attempt to provide a formal basis for comparing computers was a listing of the various characteristics of different computers published by Adams Associates. This listing has been called an Adams chart; it is still published by Keydata and typifies a simple portrayal of the classical features of computers manufactured worldwide. In the graphics area, Adams Associates also published the 〈Computer Display Review) which listed the features of graphics equipment; it was continued by Keydata and is now published by GML Corporation.

As pointed out in [17], the limitation of the Adams chart is the inference that performance can be meaningfully predicted from these classic features. It has been well established that the use of such raw speed parameters as clock speed, arithmetic speed, memory speed, word size or I/O rate can be misleading in predicting comparative performance between different systems. Over the years, many people have taken different combinations of these classic 
features and have used these combinations as figures of merit to infer performance measures.

Any listing of simple features fails to incorporate the differences that each system designer included to improve his system. The power of each instruction set combined with each system's architecture is not indicated; the effectiveness of system software is not considered; and factors for evaluating special capabilities such as multiprogramming or multiprocessing are lacking.

\section{Instruction Mixes}

A major advance over the feature analysis approaches was the development by the Auerbach Corporation of a standard set of small problems which could be programmed by experts for the variety of different machines and configurations under consideration. The results yielded the amount of memory required, the amount of code and similar detail. The implication is that performance on these standard problems is indicative of the performance on actual user problems, and that small-problem performance is indicative of large-problem performance.

As Johnson observes, however, all instruction mixes [17] suffer from the limitations that the actual mix in use may or may not correspond to that of the "standard" mix. Further, none of the instruction mixes yet devised provide a reliable indication of full load behavior of computing systems. This is an especially serious shortcoming when attempting to predict the performance of multiprogramming or multiprocessing systems. The full load performance of such systems does not appear to be proportional to its small-problem performance. Nevertheless, simple instruction mixes have been widely used over the years because they are simple, easy to use, and provide a reproducible evaluation methodology.

The application of this technique to the analysis of graphic systems is reflected in the set of test patterns which was developed by Adams Associated for their <Computer Display Review $>$. These patterns were designed to be coded for each display system to be evaluated. One immediate result would be a comparison of the number of words necessary to code the pattern in its entirety. The results of running each pattern were the percentage of the pattern that could be displayed flicker free - a measure of the capacity of the display for applications of which the test 
patterns were supposedly representative. were the following:

Alphanumeric Test Pattern - The alphanumeric test pattern is representative of applications requiring the display of tabular or free-form character data. Figure 4 illustrates this test pattern.

Weather Map Test Pattern - The weather map test pattern is representative of a class of applications including geographical or mathematical contour mapping as well as sheet metal styling. Figure 5 illustrates this test pattern.

Graph Test pattern - Graphs and charts are very common displays, both in business and scientific applications. Figure 6 illustrates this test pattern.

Architectural Drawing Test Pattern - The architectural drawing test pattern is representative of applications where a large quantity of unstructured data must be displayed with high precision. Such applications include circuit board layout and mechanical design. Figure 7 illustrates this test pattern.

Electronic Schematic Test Pattern - The electronic schematic test pattern is representative of applications where pictures are constructed hierarchically, using repeated instances of certain patterns or subpictures. Such applications include logical design and certain layout problems and mechanical analysis systems. Figure 8 illustrates this test pattern.

\section{Kernels}

A more sophisticated version of the instruction mix approach to the anlysis of system performance uses "kernels." A kernel is a complete nucleus problem; meaningful kernel problems are selected according to the type of application of interest, e.g., a matrix inversion for scientific problems or a small sort for business applications. The execution time of a set of such problems is assumed indicative of the system's execution of the whole application. When kernels are programmed by experts on their respective machines and the actual software of that system is used, the results can be good indicators of that small-problem behavior of that system. 


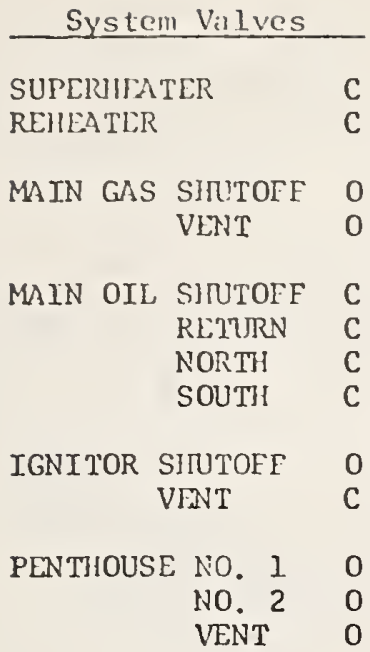

System Status

*TRIPPED *

c

0
0

C

C

C

0

0

VENT 0
System Signals

STEAM PRESSURE N

FURNACL PRESSURE N

GAS TEMITRATURE N

COMBUSTION - M

FORCED DRNTT FAN R

AIR HEATLR

IGNITOR CIIARGED Y

GAS READY

OIL RFADY N

DUAL PERUISSTVE N

MODE SWITCII

PURGE REQUIRED

BURNERS

$\begin{array}{lllllllllll} & 1 & 2 & 3 & 4 & 5 & 6 & 7 & 8 & 9 & 10\end{array}$

IGNITOR

FLAKE -

TRANS

SIIUTOIF

MAIN FIAME - $\quad-\quad$ N F F F

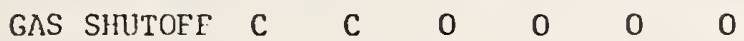

$\begin{array}{rlllll}\text { OIL SHUTOFF } & \mathrm{C} & \mathrm{C} & \mathrm{C} & \mathrm{C} & \mathrm{C} \\ \text { UNIT } & 0 & 0 & 0 & 0 & 0\end{array}$

ATOM I I I I I

PURGL C $\quad \mathrm{C} \quad \mathrm{C} \quad \mathrm{C} \quad \mathrm{C}$

$\begin{array}{llllll}\mathrm{COOL} & \mathrm{C} & \mathrm{C} & \mathrm{C} & \mathrm{C} & \mathrm{C}\end{array}$

DAMPER

$0 \quad 0$

0

$0 \quad 0$

$0 \quad 0$

CONTROL

$$
\begin{aligned}
& \begin{array}{rllllllllll}
\text { IGNITCR } & - & - & - & - & \bar{x} & \bar{x} & \bar{X} & - & - & - \\
\text { GAS } & - & - & \bar{X} & \bar{X} & \bar{X} & \bar{X} & \bar{x} & - & - & -
\end{array}
\end{aligned}
$$

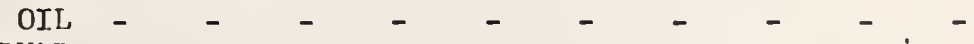

$$
\begin{aligned}
& \begin{array}{rlllllllllll}
\text { DUAL } & - & \bar{x} & - & - & - & - & - & - & - & -
\end{array}
\end{aligned}
$$

Figure 4

\section{ALPHANUMERIC DISPLAY TEST PATIERN}

(C) Copyright GML Corporation 


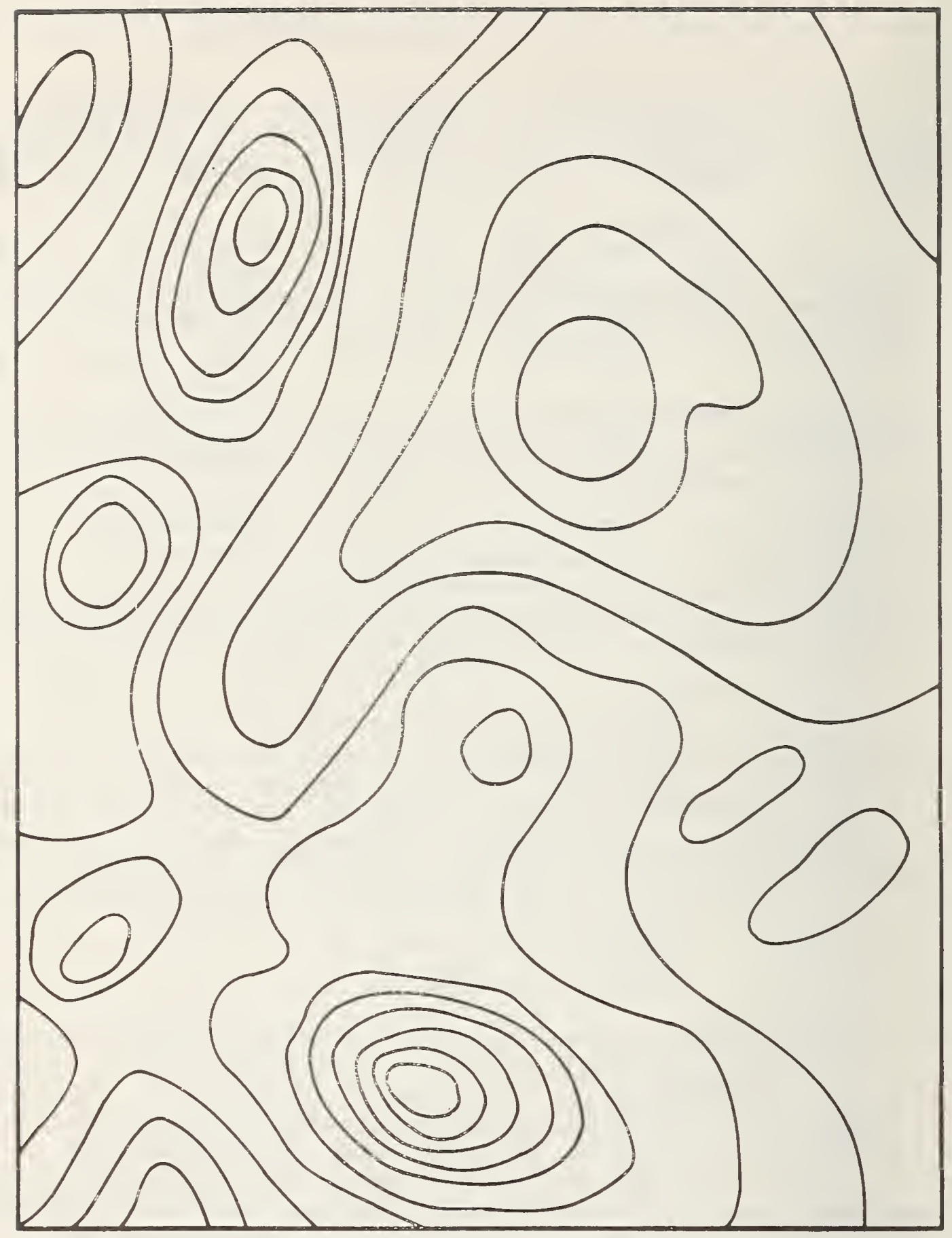

Figure 5

WEATHER MAP TEST PATTERN

(C) Copyright GML Corporation 


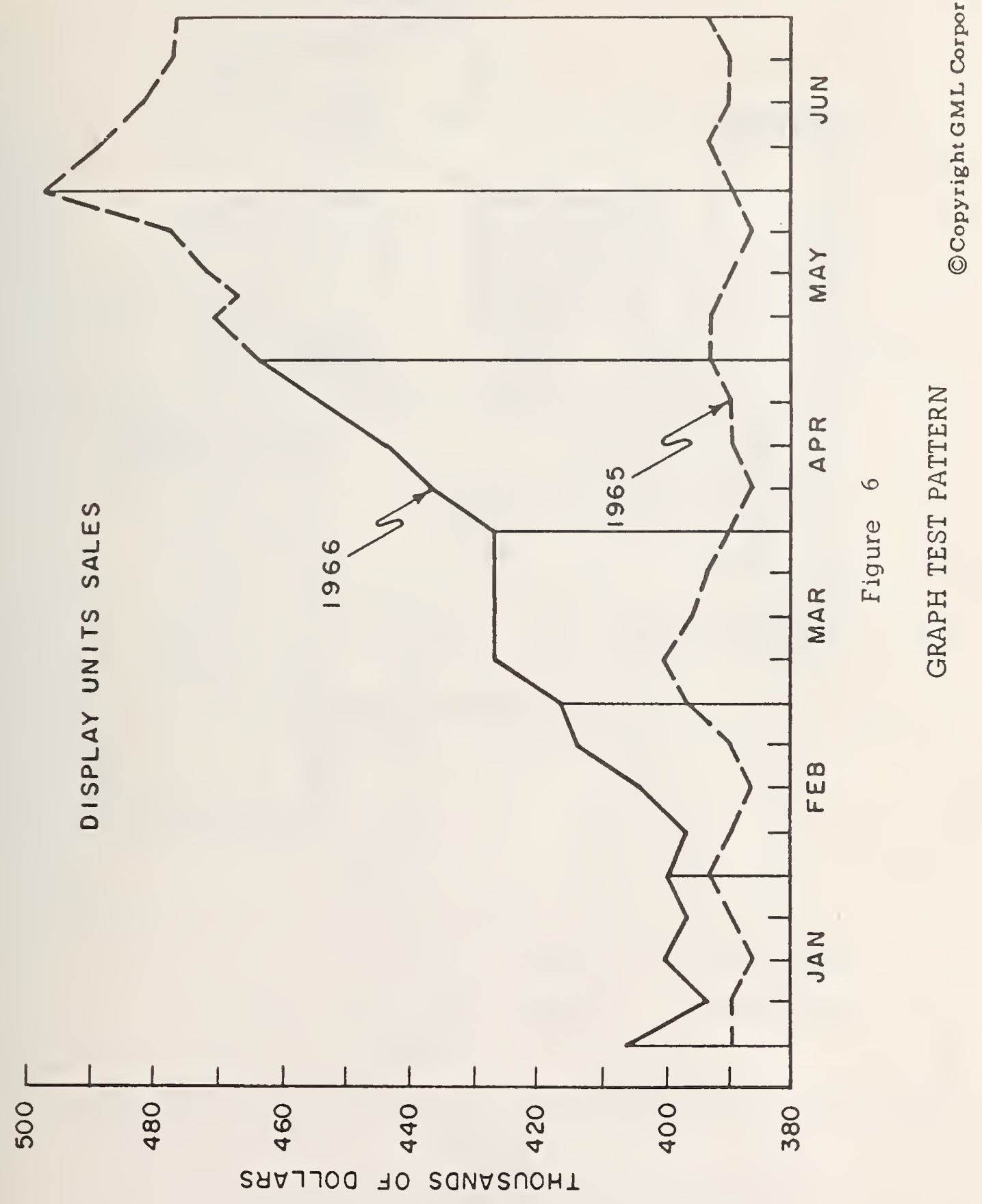




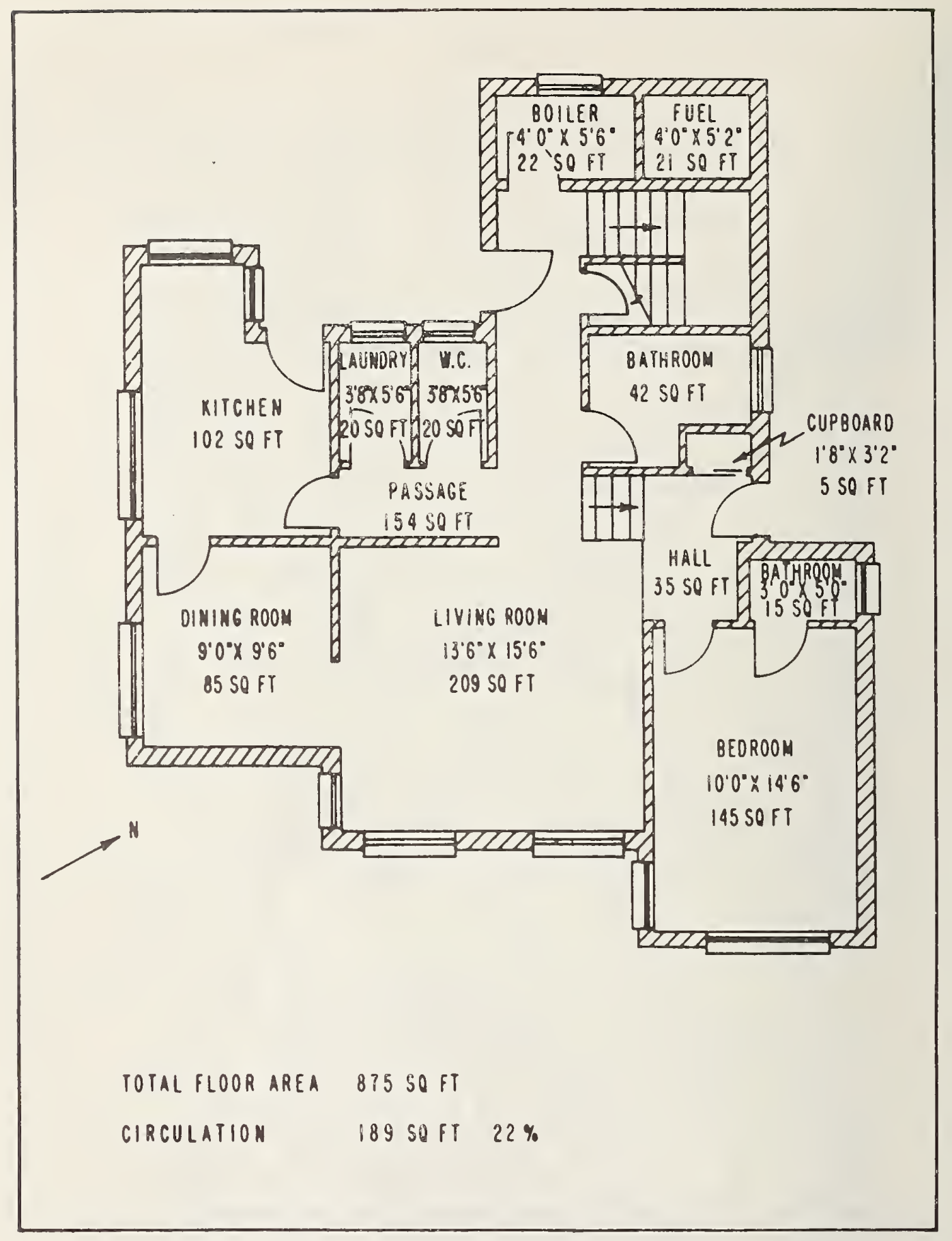

Figure 7

ARCHITECTURAL DRAWING TEST PATTERN

C) Copyright GML Corporation 


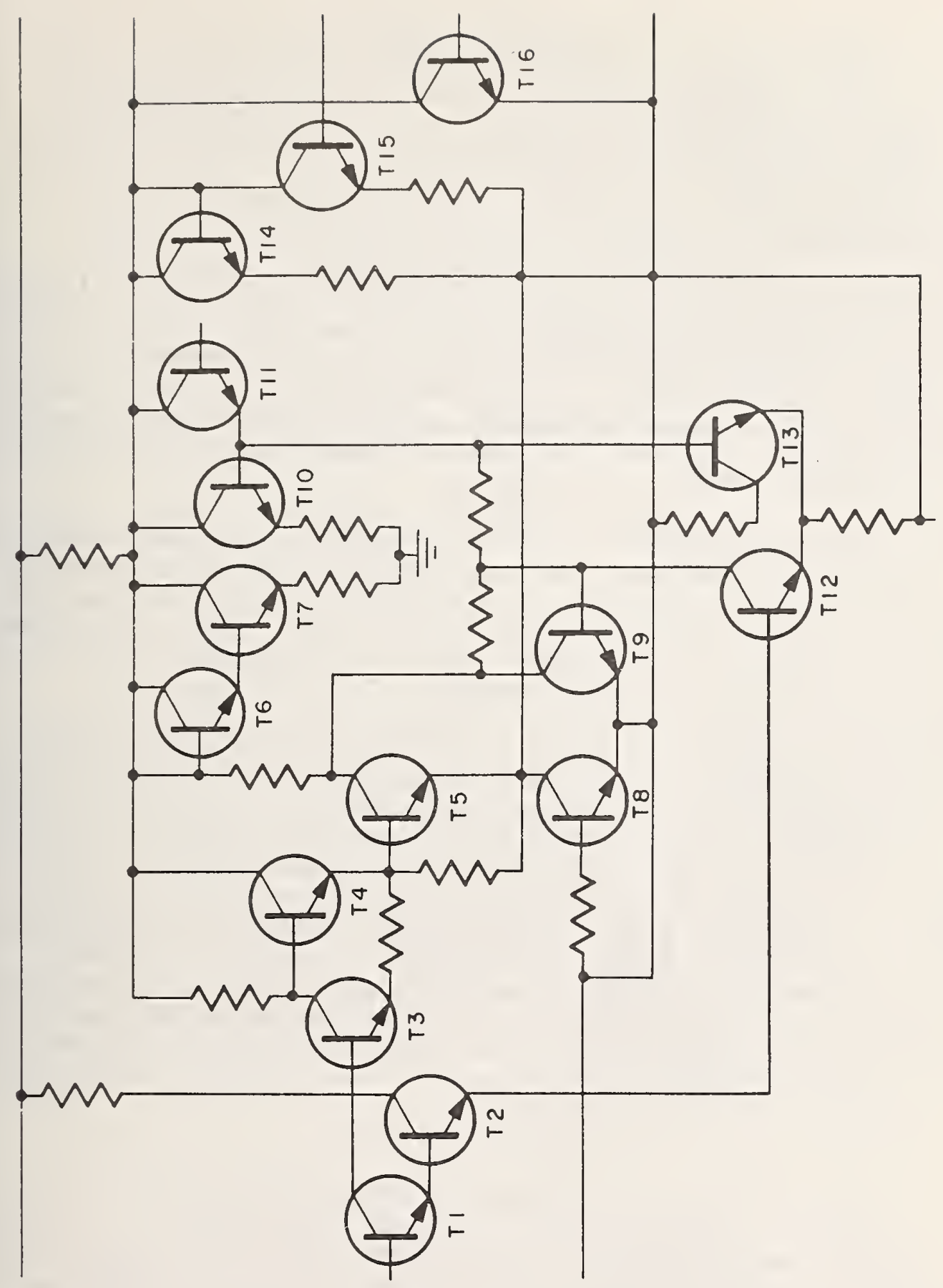

Figure 8

ELECTRONIC SCHEMATIC TEST PATTERN

(C) Copyright GML Corporation 
The most reliable and accurate measurement technique that has been developed to analyze total system performance is to actually code and run a representative mix of complete programs selected from those that are to be run in the actual application. Such sample programs are called "benchmarks." However, pitfalls still exist: the benchmark programs run in sequence may not accurately represent the nature of the work to be performed. Combining several benchmarks partially alleviates this problem, but choosing the right combination of benchmarks is also difficult. Still, as long as benchmarks are run in the large and small mixes expected in the actual operation, a good indication can be obtained of both the large and small problem behavior of the system.

The real limitations of the benchmark approach are that it takes a large effort to develop the sample programs and to prepare realistic data. The task is difficult enough for batch-oriented computer systems for which some libraries of programs written in standard compiler languages have been developed for benchmark purposes. It is nearly an impossible task for computer graphics systems where the programming systems for each are completely different. Also, the results of running benchmarks are only as valid as the benchmarks are representative of the real application mix. Graphics programs typically are composed of a number of different modules with radically different

characteristics. Furthermore, an essential part of the graphics programs are the sequences of operator inputs which direct the execution paths of such programs. These sequences are difficult to model and expensive to actually generate in a test situation.* Thus, developing benchmarks for graphics systems which are truly representative of actual applications is difficult to do and the benchmarks are equally difficult to run.

\section{Simulation}

A final technique which can be used used in performance analysis is simulation. Simulation cuts across the two general approaches of observation and analysis. To use this technique, a model is constructed of the system under consideration and the performance of this model is "observed" under the desired conditions. The model

- - - - -

* Work is in progress by a number of researchers at The Mitre Corporation and at the National Bureau of Standards on "Terminal Environment Simulators" which can serve as drivers for benchmark programs for interactive svitems. 
represents a simplification of the actual system which is constructed from analysis of the system. If the model accurately represents all the salient features of the actual, when it is run with the desired (simulated) workload the result is analogous to observing the actual system.

of course, the results of simulation can be no better than the many assumptions that go into the construction of the model and into the design of the simulator. Construciing a computer system simulator for performance evaluation purposes is, as has been pointed out, [4] not an easy task. If the level of simulation is too fine, the simulator will be too costly to use. If the level is too gross, not enough information will be yielded. Despite these difficulties, simulation is becoming much more widely used, and a good simulator properly used may be one of the better tools for predictin system performance accurately. As we shall see presently, it is also a technique which can and has been used to analyze computer graphics systems.

4. Cost Analysis

The principal problem of the cost analysis of computer systems is to express all the costs of alternative system proposals in a form suitable for analysis. This requires that ALL relevant costs be included, and that all costs be expressed in a comparable form. The question of which costs to include has been well treated in the literature. Joslin [18] presents a detailed analysis of all the types of costs which must be included in evaluating a system design alternative. The main complication in many cases is the need to include development costs in the analysis which are not known in advance but which must be estimated.

\section{Cost Estimates}

If two or more proposed systems are to be compared, it is necessary to compare the amount of development effort required for each. Data for such an analysis is "softer" than data describing the pricing of components or even charges for the use of components. Substantial work has been done in developing formal techniques for estimating such costs $[20,24]$, but their main effect has been to reduce the margin of error from outrageous to large. Yet the estimates made of the cost to implement functions in either the central site or the satellite may be the dominant factor in system selection. 
For example, large systems today all come with operating systems, and most with communications handlers as well. On the other hand, few minicomputers come with the type of operating systems which would be required to shift some functions from the central site to the satellite. The cost to implement such an operating system may be critical to determining the cost-effectiveness of the proposed division of labor.

Of course, given a large enough number of satellite systems over which to share the total development costs, the average development cost may be made arbitrarily low. Thus, an honest and realistic assessment of the expected number of replications must also be made. This is primarily a market research problem.

\section{Comparable Form}

The other problem of cost analysis is to express all costs in comparable forms. The assignment of the appropriate unit costs to the use of the various resources is of critical importance. A controversy may arise in the analysis of graphic systems over whether to price at average or incremental costs. For resources which would not be presert if there were no graphics system, incremental and average costs are the same. However, if existing facilities are used part time for graphics, the incremental costs will be less than the average costs. If any tradeoff is to be valid, costs for resources in the central system and at the satelite must be comparable. This can be accomplished by using, in all cases, equivalent monthly rental charges or average resource utilization charges, as appropriate.*

For example, a graphics processor cannot be utilized at no cost simply because it is owned and always available. An equivalent monthly rental charge must be determined and used to derive unit-time operating charges so that they may be aggregated with the charges for the central processor, which are likely in this form already. Likewise, file storage charges for devices at either location must be represented in equivalent, non-zero terms.

Actually, the costs used for the analysis may vary according to the purpose of the analysis. An individual company considering adding a graphics capability to an existing facility will want to use incremental costs in order to determine if the addition is warranted. An analyst wishing to compare two alternative graphics systems in the abstract would prefer to use a measure which assigns a cost to resources irrespective of the use to which they are put. 
The concept of fixed versus variable costs is also a relevant one. Development costs such as design and programming costs are fixed, as are hardware components in the graphics terminal since they cannot be used for any other purpose (their cost is fixed regardless of utilization rate). In contrast, the use of central site resources such as storage and the execution of programs are variable costs, since the central computer is shared by a large number of users who only pay for the units of each resource as they are used. The costs for some resources may be either fixed or variable depending on the particular arrangements. For example, communications charges would be fixed if a leased line were used and variable if dial-up facilities were used.

The significance of expressing the charges in this manner is that where fixed charges dominate, total costs are relatively constant but the unit operating costs for a given configuration are very sensitive to the level of usage. In such situations, only high utilization of the graphic equipment can bring down the unit cost [26]. The sensitivity of unit costs to level of usage may be reduced if fixed costs can be converted to variable costs. For example, a higher speed communication link may make it possible to store programs and data at the central computer which are used by the graphics program at the satellite. This would permit the amount of memory at the satellite, which represents a fixed cost, to be reduced in favor of use of storage at the central site, which usually represents a variable cost.

However, the argument goes two ways. Above a certain level of utilization, called the "breakeven point", it is more economical to convert variable expenses to fixed ones. Communications charges are an excellent example -- above a certain level of utilization it is cheaper to lease a full time link than to make a call each time. So estimates of the level of utilization for a system may still be critical to system design decisions.

Generally, the problems of cost analysis for computer systems are well-understood (though they may not be well-solyed). Computer graphics systems are not so unique in this regard that they present any special problems. Perhaps the greatest challenge for cost analysis is to obtain results in a form such that the marginal costs of performance were obvious or could be easily determined. This would permit the costs for improved performance or the 
savings from reduced performance to be more easily used in making design decisions. A parametric formulation explicitly relating costs to level of performance and utilization rates could serve as input to a decision model.

\section{Cost-Effectiveness}

Cost-effectiveness analysis is a technique used to compare alternative systems where the benefits to be derived cannot be determined quantitatively. The object of cost-effectiveness analysis is to select either the system with lowest cost for a given level of performance or greatest performance for a given level of cost. The method requires that either the costs or the performance associated with all the systems under consideration be equal. If both costs and performance are different for any two systems to be analyzed, then cost-effectiveness analysis is impossible since the parameters have different dimensions and may not be compared.

The application of cost-effectiveness analysis is failly straightforward. First it must be decided which parameter to hold constant -- cost or performance. Cost is frequently held constant when there is no absolute level of performance which is required. In this case, a fixed amount of money is made available and the analysis seeks the system with which offers the greatest performance. A measurement criteria is selected and the systems are evaluated according to that measure. The system which measures the greatest --for identical cost-- is the most cost-effective. Tradeoffs between system components may be investigated by varying the mix of components subject to the constraint that total system cost remain the same.

The alternative approach is to specify in advance the performance required of the system. The system is selected which offers at least that level of performance for the least cost. Performance in excess of the specified capabilities is ignored in the analysis. For such systems, tradeoffs focus on the reduction of performance (and with it, cost) to the point where performance just equals that required.

Many studies have been published discussing the tradeoffs involved in the design of graphics systems $[16,22,25,31$, 32]. However, few published results show any serious attempt to quantify these tradeoffs. Quantification is necessary if a true cost-effectiveness analysis is to be 
performed. One of the first published results of a quantitative analysis of design. tradeoffs was Foley's study of satellite graphics systems [11].

\section{Foley's Analysis}

Foley defined optimum design of a computer graphics system as "maximizing a display system"s performance subject to a cost constraint." In his view, optimum display design can be thought of as a resource allocation problem. The resources are dollars which can be allocated to the purchase of display subsystems of differing individual performance. System response time was employed as the sole measure of system performance. (Minimizing response time means maximizing performance). Total system performance is determined from a model of how the subsystems fit together. The parameters of the model are functions of the capabilities of the graphic hardware and of the computational requirements of the graphics application. The model can be analyzed using numerical queueing analysis or simulation to obtain an average response time prediction. By applying an optimization procedure, the "best" praphics system configuration, subject to a cost constraint, may be found for several applications. The optimum configurations are in turn used to find general system design guidelines.

Foley used a combination of kernels and instruction mix techniques to evaluate the computer power of the remote display controller. Basically a set of "display commands" was defined. These commands are at a level higher than machine instructions but lower than a high level language. The commands are coded in the machine language of the controller and timed. Each display command timing is weighted by a factor representative of the relative frequency of execution of that command for a particular application. The greater the value of the weighted instruction execution rate (the reciprocal of the command execution timing) the better suited is the corresponding controller for the application. The full account of Foley 's research [10] indicates that he also employed the Adams test patterns in a similar manner to compare the suitability of display controllers for different applications.

Foley's analyses yielded curves of the form shown in Figure 9. Such curves show the price which must be paid for a given level of responsiveness. Performance is actually the reciprocal of response time, so that figure 9 illustrates the relation between performance (output) and cost (input). The decreasing slope of the curve reflects 


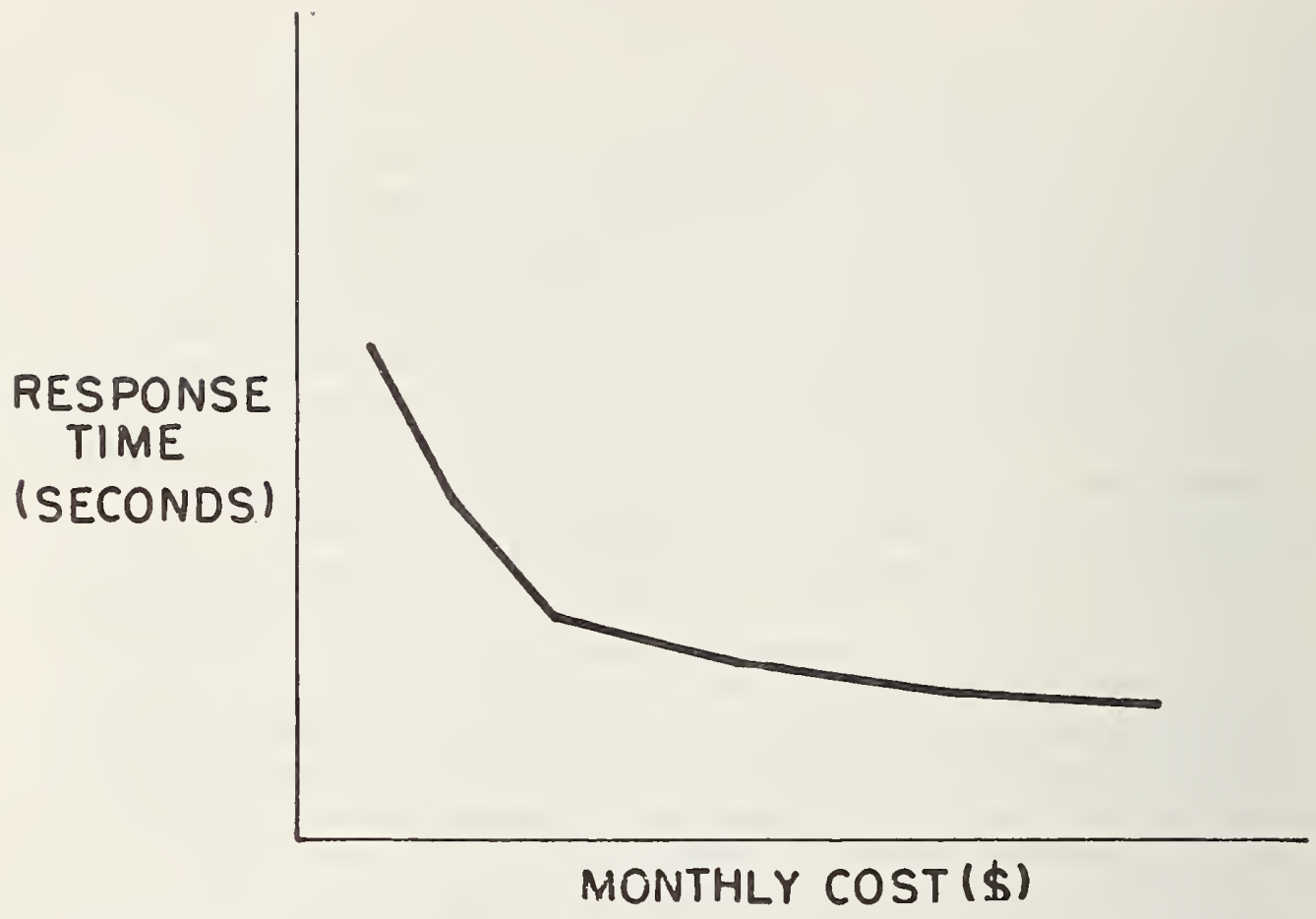

Figure 9. Typical Result of Foley's Analysis 
the decreasing marginal productivity of additional units of cost in Improving performance. The analyses also revealed that different regions on the curve were associated with the upgrading of different components in the system. Simply stated, this means that different components were being upgraded when performance was improving most rapidly than when performance was increasing less rapidly. Thus the analysis yielded a set of decision rules indicating the order in which a limited amount of additional money should be spent.

\section{Cislo's Approach: Simulation}

Cislo expanded on Foley's approach by considering a more complex model of a graphics system in greater detail [6]. Foley neglected the cost of resources at the central computer; Cislo's study includes them. Cislo also modeled a multiterminal system in which each terminal is used for a different application; this went beyond Foley's analysis. Finally, Cislo employed simulation in contrast to Foley's use of queveing analysis.

Cislo's model of a graphic system decomposed the operation of the system into a number of low level operations which might be viewed as the kernel problems of a display system. The activities included in the model are listed in Table 1; Figure 10 illustrates the model itself. A GPSS program based on the model was written and used to exercise it. The program simulated operation of the system by generating transactions which correspond to user requests. The interarrival time between requests was determined randomly from a negative exponential distribution. Similarly, the selection of the appropriate routines to process the request was determined stochastically. 


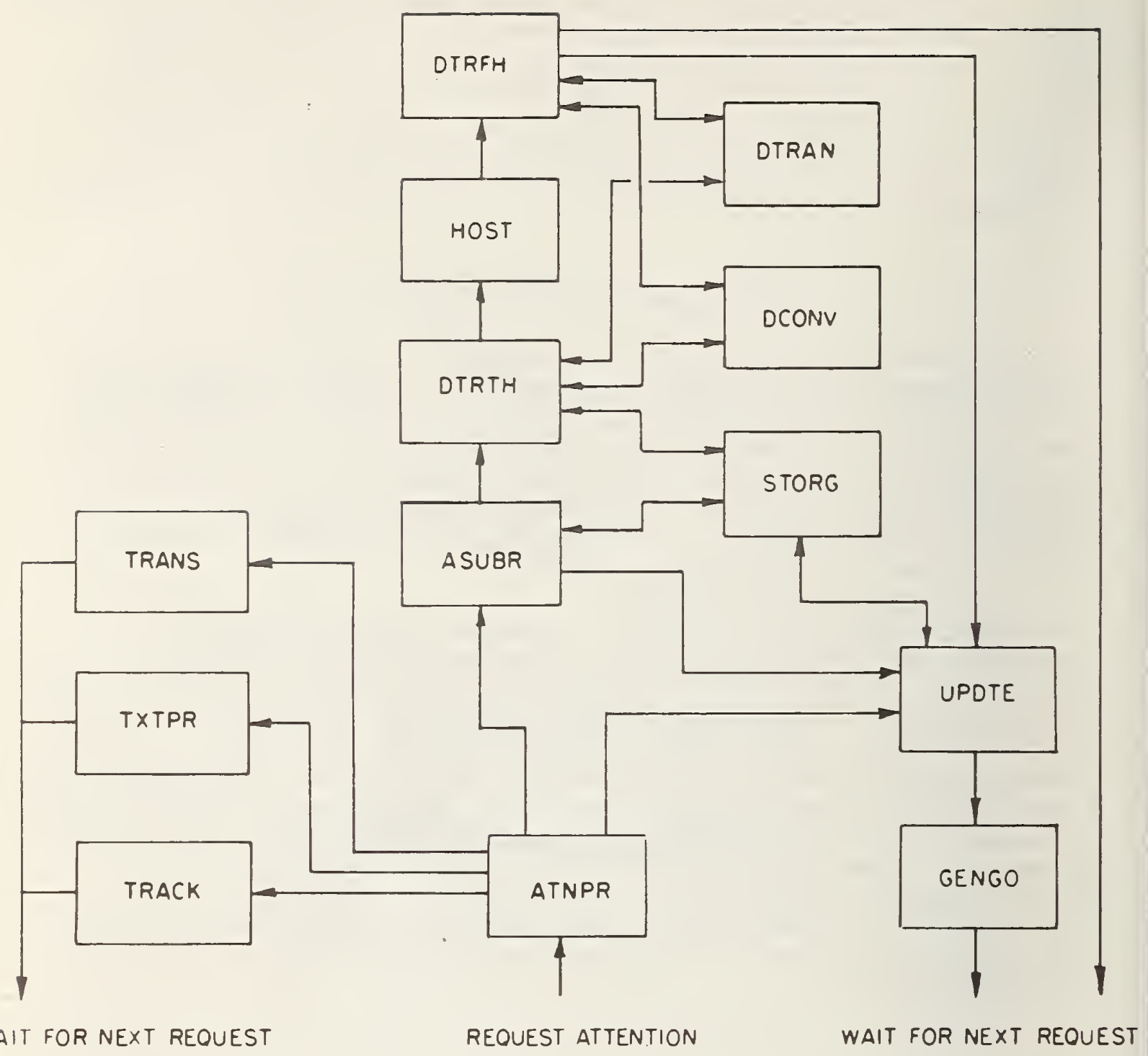

Figure 10. Cislo's Graphic System Model 
Activity

Mnemonic
ATNPR

TRANS

TXTPR

TRACK

ASUBR

DTRTH

HOST

DT REH

DCONV

STORG

UPDTE

GENGO

\section{Table 1. Model Activities}

The parameters of the model are very similar to those of Foley's model and the data were similarly obtained.

Published data were used for simple parameters such as instruction execution and data transmission rates, and simple test programs were generated for the estimation of such parameters as the time required to generate graphic orders. Application-dependent parameters such as the probability of generating a given number of graphic orders were much more difficult to estimate, and in many cases were simply assumed.

In exercising the model, it was decided to hold these latter parameters constant while varying the hardware parameters. Accordingly, the operation of eight different hardware configurations, involving changes to the main CPU, display CPU and data transmission facility, was simulated. The results were in accordance with Foley's findings, but the method accorded much more detailed descriptions of system activity. The expanded version of the model which would handle multiple independent graphics consoles was described but not implemented.

\section{Validity of Indicators}

These techniques which have just been described offer much hope of permitting the analysis of computer graphics to be performed on a much more systematic and quantitative basis. The value of the analysis, however, is dependent on the validity of the variable(s) which is optimized as an indicator of total system performance. Accordingly, this 
discussion of cost-effectiveness is concluded with a discussion of this question.

\section{Response Time}

The response time provided to a user has long been considered a critical parameter in the performance of interactive systems. The general approach of system designers to this parameter has either been to "minimize it", subject to available monetary resources, or to insist on a minimum response time, e.g., 2 second response $95 \%$ of the time, regardless of the cost. This approach is overly simplistic and may be far from cost-effective for a number of reasons.

First of all, not all interactive tasks require the same responsiveness of the computer. Miller [23] has shown that there are several classes of interactive activity with quite different response requirements. One class is the input of data by various means. An immediate response of no longer than . 1 - .2 seconds is required for this class to signify acceptance of the data. A second class is characterized by a user engaged in high-intensity "brainstorming" requiring the ready access of data from his own "short-term memory." Such activity requires no longer than a two-second response in order that the chain of thought not be broken. A final class includes those activities which complete a subjective (sub)task or (sub)purpose. More extended delays (up to 15 seconds or more) may be permitted following such an activity completion, or "closure", than in the process of obtaining a closure.

These findings may have an important impact on system design, since alternative methods exist to provide each type of response. For example, verification feedback and simple data manipulations may be supported on a so-called "intelligent terminal" with its own local mini-computer. Since the response from complex application-dependent computations may be permitted to be less rapid, these may be provided by a large time-shared computer, possibly located at some remote location and connected by a communications circuit. A cost-effective design will assign the function of providing each type of response to the facility which can meet the required response and meet it at least cost.

Other factors may also be considered relating to response time. A uniform response time has come to be recognized as very important (in contrast to a response time which varies widely from transaction to transaction) -- so much so that 
in some applications the responsiveness of the system is artificially delayed when it falls below the desired value, so that the variability of response is thereby reduced (at the expense of lower average response time).

Finally, some experimentation has been performed into the effects of restricting the free access to the computer after it has responded to each major request (similar to a closure) [3]. It was found that "users tend to become dissatisfied if mild restraint is placed on their free interaction with the computer." However, "they also tend to problem solve more effectively, using less computer time and less of their own time in the process." The authors suggest that "the results cast doubts on the validity of user acceptance as a general index of system effectiveness."

Clearly, the matter of the responsiveness required of a graphics system is not a straightforward question, and it does require serious consideration on the part of the system designer.* The dilemma is exacerbated by the demonstrated sensitivity of responsiveness to additional investment [11].

\section{Other Indicators}

Another effect of the over-reliance by analysts on response time as the sole measure of performance has been the neglect of a number of other important performance characteristics. These have been conveniently divided into task-dependent factors and human-dependent factors [2]. Task-dependent factors include screen size, message size, message format, erasability, color and half-tone capability in addition to response time. These factors will vary with importance according to the particular application; hence a weighting approach should be used when evaluating systems according to these factors.

Human-dependent factors, or more simply human factors, permit the system to be evaluated on its usability by human beings. Such factors include brightness, contrast, resolution, readability and the visual fidelity of the display. These factors are not as importance as they were in the early days of display system design when they were less-well understood, but they should still be validated for any system under consideration. Other ergonomic

* An interesting application of response time data to a design tradeoff problem is presented in [33]. 
considerations might also be important in special cases, for example if the display were meant for group viewing. Again, the needs of the particular application will dictate requirements. A table in [2] presents a cross reference of desirable characteristics for specific display applications. Both task-dependent and human-dependent factors are included.

\section{Benefit Analysis}

The benefits from a computer system arise from performing some tasks faster or qualitatively better than previous methods. Benefits are generally measured relative to the previous method. The problem is to assign actual dollar values to the benefits measured.

Methodologies for performing benefit analysis of computer systems are analogous to the methodologies for evaluating system performance. There are two general approaches: empirical test (benchmarks) and parametric analysis.

An empirical test to determine the benefits of a given system would require two control groups and a typical task. One group would perform the task according to the old or baseline method; the other group would perform the task with the new system. Two types of benefits could be measured from such an experiment: cost savings from using the new system to achieve the same level of performance as the old method, and benefits from any performance levels achieved in excess of what was normally accomplished the old way.

The other approach of assessing benefits by parametric analysis involves decomposing tasks into a number of elements. The benefits from improved performance in each element must be assessed, and then the old and new system can be compared on each element. For each application, the required tasks can be reconstructed from an appropriate aggregation of elements (where the parameters specify the proportions for each). In this way the benefits from doing the particular application with the new system can be estimated.

Unfortunately, very few published results of either type of study are extent in the literature. Productivity claims of 500\% and above for the first type of study have been bandied about at professional society meetings, but the supporting evidence has not been published, either because it did not exist in satisfactory form or because such data 
was considered proprietary. What are most commonly found are comparisons of an installed system with the old way of doing things, without controls for any other variables. Sackman [28] has presented a summary of several such studies comparing on-line vs. off-line performance on a number of different tasks $[1,9,12,14,27,29]$. The shortcomings of the experimental methodology employed in most of these studies has been critiqued [21].

Occasional studies of the second type have been published, but the focus has generally been so narrow that the results could not be generalized [5]. An example of a better study of this type is Gold's study of problem-solving performance in time-sharing versus batch processing [13].

\section{Gold's Study}

Using a programming language available in both batch and on-line environments, Gold "focused on a development of a methodology through which time shared computer system usare could be evaluated." Eive categories of variables were included in the methodology:

Cost of using the system

System performance

Turnaround time

The mode of learning resultant from system use The attitudes of the system users

Principal variables associated with the measurement of the computer system features included computer response delays, degree of interaction between the user and the computer system, and quality of response in feedback mechanisms and programming systems.

User attitudes are defined in the study as "the degree to which the computer system characteristics appear to the user to facilitate or hinder him in the attainment of his short and long term objectives." User behavior is further characterized in the study as "the degree to which the user relegates programmable problem solving to the computer system." Performance for the purposes of the study is defined as "a measure of the output of the man-computer system which is arrived at independently of the user's behavior or the computer system used."

The following are the significant findings of the study with respect to user behavior: 
1. The users of the time sharing system interacted with their computer system more than three times as often as did the batch-processing users.

2. There was no significant difference between the reasons advanced by the time sharing or batch-processing users for initiating computer actions.

3. There was a strong relationship between a batch-processing user's performance level and the number of computer interactions which produced usable output. For the time sharing user, the correlation between performance and the number of sessions with the time shared computer console is strongest.

4. Much more favorable attitudes toward the time shared computer system, its use and the results produced through it were evidenced.

With respect to quality and cost of results, the following results were reported:

1. Use of the time sharing system resulted in a higher level of objective performance than use of the batch processing system. Also, the "perception and understanding of the problem" of the time sharing users was evaluated as significantly higher than that of the batch users.

2. The total cost of time sharing and batch usage did not appear to differ appreciably. Higher computer costs and lower man costs were found with time sharing usage, however. There were indications that the total cost for equivalent objective performance would have been less for the time sharing users.

\section{A Suggested Approach}

Studies of the type just discussed are limited in that they may not be generalized beyond the specific sample activities under investigation. There has been no attempt to decompose the overall activity into more basic application-oriented functions, and to model different activities on the basis of these functions.

Application-oriented functions are different in character than the type of model activities developed by Cislo. For example, text editing and geometric sketching might be two tasks elements which would be used in different proportions 
in a particular graphics application. Determing the benefits of improved performance on each of these tasks would provide the necessary data to determine the benefits for an application comprised solely of those two activities. A sample list of kernel activities for benefit analys is is presented in Table 2. Other elements need to be identified and analyzed.

Text Editing - original input and modification

Sketching - original input of geometric data

Updating - modification of geometric data

Inquiry - transaction processing

Directing - on-line control of other operations

Monitoring - of other operations

Mechanization of Output - production of finished drawings Rapid Turnaround - should be isolated as a separate benefit

Table 2. Sample Kernel Graphic Tasks for Benefit Analysis

The paradigm suggested would employ first analysis, then experimentation, then synthesis and finally validation by means of experimentation again. The goal.is to isolate the individual task activities in an application, experimentally determine the individual benefits for each, parametrically aggregate these benefits to determine the benefits for the entire application and finally to validate these results by determining directly the benefits for the entire application. Since part of the paradigm includes experimentation using the application in its whole or total form, an application of limited complexity should be chosen.

Having chosen such an application, it will be necessary to try to decompose it into discrete task areas. This is a procedure for which no formal rules exist. Common sense and some understanding of what constitute "closures"[23] in the psychological sense will have to guide this analysis. The activities should be large enough that they may be analyzed and the benefits from each determined, but they should also be sufficiently limited in scope that they may be experimentally manipulated reasonably well and that they may be used as building blocks to characterize full applications.

Having chosen the task areas, or kernels, experiments will be designed after Gold's model to determine the benefits derived from performing each task on a model 
graphics system as compared with doing it some other (baseline) way. Experimental procedures employing two or more sample grouos and a control group are well understood and should be followed. Statistical techniques such as analysis of variance may be useful both in establishing the level of benefits and validating the initial choice of the groups.

The final validation of the approach comes after an application is modeled by the task groups and the benefits are predicted and verified by experimentation. This will require an experiment which treats the entire application -which we have been trying to avoid -- but this is necessary a few times in order to validate the approach. If the approach can be validated, experiments on that scale will not be necessary again.

Studies such as this are but a first step in the development of kernel problems for the assessment of benefit values for particular systems. Many more studies, and preferably a systematic project with the stated objective of disaggregating the application-oriented functions of a graphics system and determining the benefits of each, are required before a parametric approach to determining the total benefits of an arbitrary system can be perfected.

\section{Synthesis: Cost-Benefit Analysis}

Cost-effectiveness analysis is valuable because it shows how to best allocate limited resources so as to optimize some specific performance objectives. However, such an analysis is inadequate for making an investment decision. Such decisions require that total system cost be compared with the value of the benefits provided by the system. This requires that acceptable levels of performance be defined, so that a point on the cost-performance curve (corresponding to a particular system) can be selected. Comparing total costs with the benefits to be derived from the system determines whether or not the system selected is cost-beneficial. Unfortunately, the problem is rarely expressed this way in the literature.

\section{Cost-Value Technique}

One approach which has been described in the literature is the so-called "cost-value technique."[19] This approach describes a formal technique for comparing computer system 
proposals which all offer slightly different features beyond the basic mandatory requirements. The procedure involves assigning a value to each of these "extras" (expressed in terms of doliars) which are credited to the cost of each proposal. The value of expansion potential, for example, is assessed and subtracted from the costs of systems which offer it. The approach is crude and subject to all the perversions of subjective judgement, but at least it forces the evaluators to think in terms of the benefits to be gained from particular features.

\section{Figure of Merit}

In another vein, Dunn [8] has sought to define a figure of merit for computer graphics systems which was free of bias towards any particular type of configuration but which is applicable to all types of configurations. However, Dunn claimed that "useful measures for interactive graphics systems are dependent upon subjective judgements." His argument was as follows:

"Any measure that is devised must reflect more than dollar costs and/or usefulness to the human and/or satisfaction achieved via a particular configuration. An interactive graphics system should and does function as an "amplifier" of the interactive human activities in conjunction with the use of computers. The amplifying function affects quality of results, quantity of work accomplished, cost-effectiveness of methodology, efficiency of effort, minimization of elapsed iime for work efforts, and so on. Amplification in this sense, then, incorporates a variety of dollar costs along with usefulness and satisfaction for the human user."

He suggested a figure of merit called "degree of amplification" or "amplification factor", symbolized as "A!" and based upon four factors: productivity, degree of interaction, extent of graphics capability and total system direct dollar costs per graphics console.

The productivity factor, $P$, is defined as the change in the rate of units of acceptable output relative to the same function being performed via a non-graphics console. The units of acceptable output are application-dependent (e.g., engineering drawings completed).

Graphics capability is a measurement factor that reflects both ease of use of the graphics console and extent of load on supporting computing systems. The graphics capability 
factor, GC, is defined as the weighted sum of capability indices for all desired features. The index values are 0 if a desired feature was not available, 1 if a desired feature was available, and -1 if a required or critical feature was not available. The weights indicated the relative importance of each feature.

The degree of interaction is measured by the interaction quotient, IQ, and is defined as a function of the ratio of the effective data rate of the connecting channel to the interaction data flow rate requirement. The IQ is expressed as a weighted sum of quotient terms for each type of interaction which could occur. Each term has the form $D R /(D O+D I)$, where $D R$ is the effective data rate of the channel and DO and DI are the output and input data rates, respectively, at the graphics console required to request and receive response for that type of interactive service request.

Direct costs are the pro-rata portions of system resources attributable to graphics support. These include the fair share of all remote, interconnecting and local hardware and software that is necessary to implement the graphics system.

Finally, the amplification factor, A!, was defined as follows:

$$
A !=\frac{d 1 P(d 2 I Q+d 3 G C)}{d 4 \$ / C}
$$

where $P$ is the productivity factor; IQ is the interaction quotient; GC is the graphics capability; \$ is the total system direct dollar costs; and $C$ is the number of graphic consoles that may be concurrently active in the system. The di are the assigned weights that reflect the significance attached by installations towards each of these factors. A! is thus a weighted measure of the change in the rate of productive output per dollar of total graphics system direct cost per active console.

\section{A Cost-Benefit Formulation}

As has been indicated, the formulation of a cost-benefit analysis must combine the results of cost-efiectiveness studies and benefit analysis. Cost-effectiveness analysis identifies those systems with the greatest performance for a given level of investment, or the least costly system for a 
given level of performance, depending on how the analysis is performed. No guidance is provided, however, for the selection of a system from a group of systems at different levels of investment and performance, because there is no way to judge if incremental improvements in performance are worth their incremental costs. Benefit analysis addresses this point by placing a value on improved levels of performance. To perform cost-benefit analysis, the benefits from different systems are systematically compared with their respective costs in a search for the system with the greatest net benefit (gross benefit minus cost).

When cost-effectiveness analyses are performed for a variety of systems at different levels of cost and performance, an optimal price-performance function is obtained. Specifically, this function is obtained either by

a) successively finding, for different levels of investment, the best level of performance obtainable for each; or

b) successively finding, for different levels of performance, the least costly system which will provide it.

Whichever procedure is followed, the result is an "efficient frontier" of systems which are optimized at every level both for cost as a function of performance and performance as a function of cost. This frontier may be expressed either as

$$
C=f_{1}(P)
$$

or

$$
P=f 2(C)
$$

A similar frontier may be obtained from benefit analysis, representing the maximum level of benefits possible for any level of investment. The derivation is easier to visualize for the curve expressing benefit as a function of performance. To obtain this function, the benefits for systems SELECTED FROM THE EFEICIENT PRICE-PERFORMANCE $F^{\prime} R O N T I E R$ at different levels of performance are successively determined. The result is a function giving the maximum benefits possible for each level of performance. This may be expressed as

$$
B=f 3(P)
$$


Cost-benefit analysis seeks the system with the maximum net benefit (the maximum of benefits minus costs). Thus, the problem is to maximize

$$
N B=B-C=f 1(P)-f 3(P)
$$

Typical curves for the functions under consideration are illustrated in figure 11. Very little must be assumed about either function to assure that a solution is possible. The benefit function must exceed the cost function at some point or the system will never even be considered for use. Both functions are also assumed to be asymptotic, for the following reasons:

1) The cost function is asymptotic in the sense that at some point, successive increments of investment provide successively smaller increments of performance. Economists would call this an illustration of the decreasing marginal efficiency of capital. In simple terms, as performance is improved, it becomes more and more costly to provide still better performance.

2) The benefit function is asymptotic in the sense that at some point, successive increments of performance will provide successively smaller increments of benefit. Economists refer to diminishing returns; in simple terms, the more of a good or service is provided, the less is the value of still more of that product.

With these justifications for drawing the curves as illustrated in figure 11, an analytic solution mav be obtained by the use of calculus. The desired maximum occurs when the first derivative of the net henefit function is zero:

$$
0=d(N B) / d P=d(f 1(P)) / d P-d(f 3(P)) / d P
$$

Subject to $N B>0$.

Actually, the cost-benefit formulation illustrated thus far has been somewhat simplistic in that it ignores utilization level. Consideration of utilization level is of primary importance because of its effect on the cost function - - increased utilization results in lower average costs. Utilization level may be of secondary importance because of its effect on benefits, e.g., the effects of scale. 


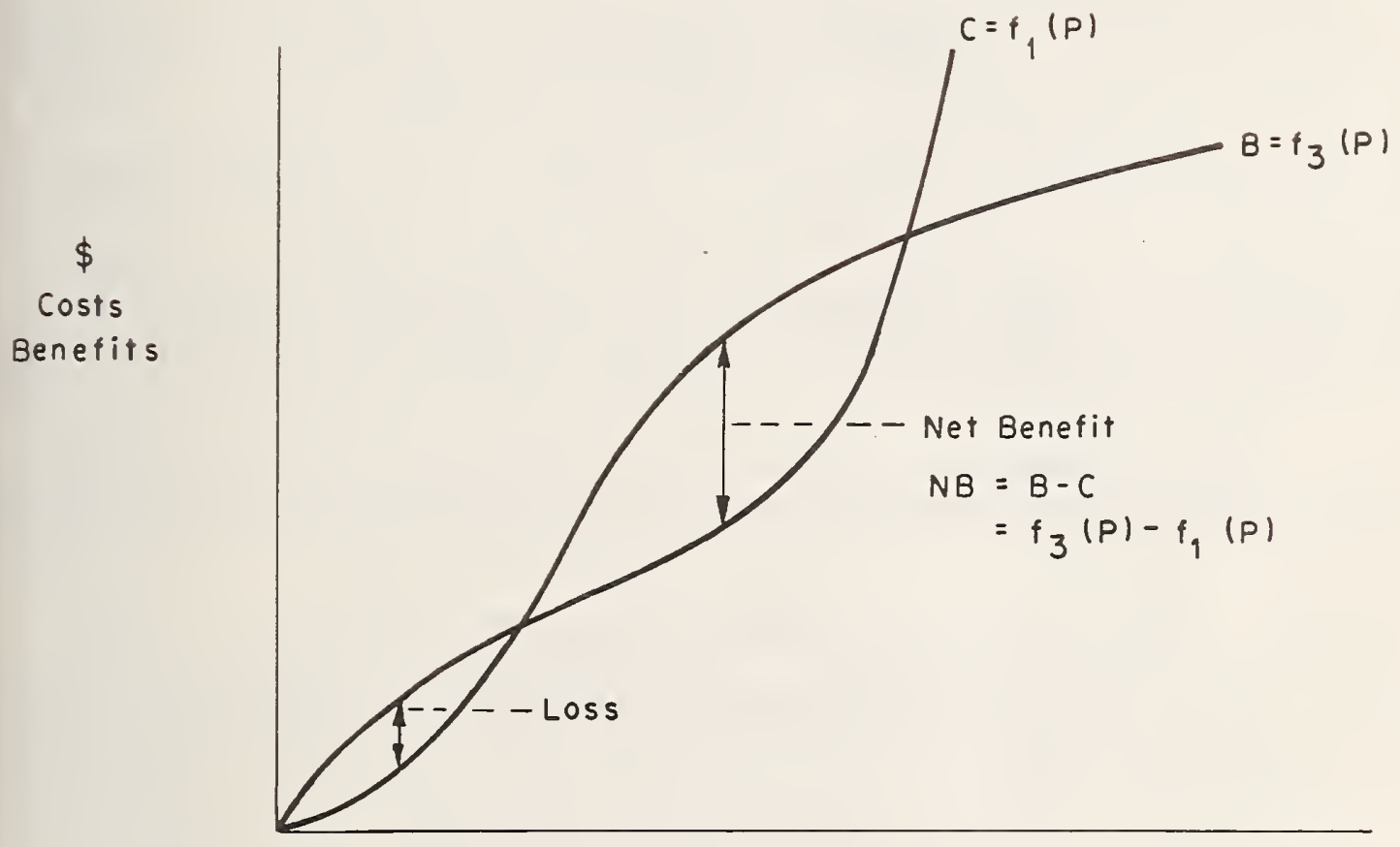

Performance

Figure 11. Graphical Presentation of Cost-Benefit Formulation 
In the reformulation of cost-benefit analysis, costs and benefits are recognized to be functions of both performance and utilization level:

$$
\begin{aligned}
& C=f 1(P, U) \\
& B=f 2(P, U)
\end{aligned}
$$

If the expected utilization level is known, it can be held constant for the analysis and the previous formulation is valid. If it is desired to permit utilization level to vary in the analysis, the graphical formulation can only be expressed as a three-dimensional graph. A solution is insured by arguments similar to those used previously. As utilization level increases incrementally, benefits will also increase, but at some point will increase less rapidly; likewise, costs will decrease, but at some point will decrease less rapidly. Thus, the effect of utilization level is asymptotic both for benefits and for cost.

The analytic solution to this formulation requires the solution of a simultaneous set of equations obtained by setting the partial derivatives equal to zero:

$$
\begin{aligned}
& 0=\partial(N B) / d P=\partial(f 1(P, U)) / d P \\
& 0=\partial(N B) / d U=\partial(f 2(P, U)) / d U
\end{aligned}
$$

Subject to $N B>0$.

Comparison With Previous Approaches

The cost-value technique may be viewed as an attempt to adjust for differences in system performances by modifying system cost. The approach is in keeping with the spirit of cost-benefit analysis; it is just too simplistic to be useful in a complex case.

Dunn's approach may be reduced to a form closer to the formulation suggested for cost-benefit analysis. Performance is actually a function of both the interaction quotient and graphic capability. Thus, the figure of merit reduces to a performance function over a cost function. All that is lacking is to relate performance to value, but this is facilitated by the way in which performance is expressed. By expressing performance in terms of productivity gains, it is easy to determine value by considering the value of performance achieved the old way. The unit benefits of the 
new system are just the unit value of output done the old way times the rate of increase of productivity.

The real shortcoming off Dunn's approach for the purposes of cost-benefit analysis is that it starts with the data it should be seeking. Data such as the graphics capability factor, the various weights, and in particular, the productivity factor, are unknown in advance. The crux of the problem is to determine the productivity gains from using a particular system. Once this is known, and the cost for using the system is determined, then the cost-benefit ratio for the system can be determined.

\section{Conclusions}

The quantitative analysis of computer graphics systems is performed at a very crude level of sophistication today. This is partially because it has a basis in the evaluation of computer systems in general, which is still a very inexact science, and partially because it deals with a system involving humans, whose performance is always difficult to assess.

As we have explained, performance evaluation of computer systems in general and graphics systems in particular can be done reasonably well. Cost analysis can be done well also; consequently so can cost-effectiveness analysis. On the other hand, benefit evaluation cannot yet be done very well, so neither can cost-benefit analysis.

Cost-effectiveness analysis is necessary but not sufficient for making investment decisions. Cost-benefit analysis reauires the output of cost-effectiveness analysis, since it requires optimal levels of performance for given levels of investment. What must then be added are results from benefit analysis to determine the optimal level of investment. However, procedures for performing benefit analysis are not well-developed. An experimental approach was outlined in this paper which applies the same types of tools to benefit analysis which have been applied to performance analysis.

Still, cost-effectiveness to be the principal tool for systems on the same order of Cost-benefit analysis is too differences between systems.

analysis will likely continue choosing among alternative cost or of performance. gross a tool to detect small Cost-benefit analysis will be 
increasingly used, however, to place the "go or no-go" investment decision on a more analytic basis.

Acknowledgments

This work was originally motivated by Dr. Guy Black of the School of Government and Business Administration, George Washington University. The continued assistance.through many manuscript drafts of Dr. James Dei Rossi of the Institute for Computer Sciences and Technology, National Bureau of Standards, is greatly appreciated.

Figures 5 through 9 are copyrighted by the GML Corporation and are used by permission.

\section{BIBLIOGRAPHY}

1 Adams, Jeanne and Cohen, Leonard. "Time-sharing vs. instant batch processing." 〈Computers and Automation>, March 1969, pp. 33-34.

2 Auerbach Info, Inc. "Design and applications of automated display systems." <Auerbach Standard EDP Reports>, Special Report, September 1958

3 Boehm, B. W., Seven, M. J. and R. A. Watson. "Interactive problem-solving -- An experimental study of "lockout effects." 〈Proc.> Spring Joint Computer Conference, 1971, pp. 205-210.

4 Calingaert, Peter. "System performance evaluation: survey and appraisal." (Communications of the ACM>, 10:1 (January 1967), pp.12-17.

5 Carlisle, James $\mathrm{H}$. "Comparing behavior at various computer display consoles in time-shared legal information." RAND Corporation Report P-4448, September 1970.

6 Cislo, Robert A. "Graphic system performance evaluation." 〈Proc.〉 1972 ACM National Conference, pp. $432-442$. 
7 Cotton, Ira W. "Network graphic attention handling." <proc.) Online 72 Symposium, Brunel University, September 1972.

8 Dunn, Robert M. "Computer graphics: capabilities and usefulness." (Proc.) SHARE XL (Denver, Colorado, 7 March 1973).

9 Erikson, W. J. "A pilot study of interactive versus noninteractive debugging." System Development Corporation, TM-3296, December 13, 1966.

10 Foley, James D. Coptimum design of computer driven display systems $>$. Doctoral Dissertation, University of Michigan, March 1969.

11 Foley, James T. "An approach to the optimum design of computer graphics systems." 〈Communications of the $\mathrm{ACM}$, 14:5 (June 1071), op. 300-390.

12 Gold, Michael M. "Methodolorv for evaluating time-shared computer usare." Unpublished Ph.D. dissertation, 1957, Massachusetts Institute of Technology, Alfred $P$. Sloan School of Management.

13 Gold, Michael M. "Timesharing and batch-processinp: an experimental comparison of their values in a problem-solving situation." <Communications of the ACM>, $12: 5$ (May 1969), pp. 249-259.

14 Grant, E. Eugene and Harold Sackman. "An exploratory investigation of programmer performance under on-line and off-line conditions." LIEEE Trans. on Human Factors in Electronics $>$ March 1967, pp. 33-48.

15 Hillegass, John R. "Systematic techniaues for computer evaluation and selection." 〈Management Services>, July-August 1969, pp. 35-38.

16 Jacobs, Lesley D. "CRT' graphics consoles - an aid to selection." Rome Air Development Center Technical Report 71-61, November 1971 .

17 Johnson, R. R. "Needed: a measure for measure." 〈Datamation>, December 15, 1970, pp. 22-30.

18 Joslin, Edward 0. "Costing the system design alternatives." <Data Management>, April 1971, pp. 23-27.

19 Joslin, Edward O. and Martin J. Mullin. "Cost-value 
technique for evaluation of computer system proposals." 〈Proc.〉 Spring Joint Computer Conference, 1964, pp. 36́-381.

20 LaBolle, V. "Development of equations for estimating the costs of computer program production." System Development Corporation, June 1956 (Published as U. S. Air Force Electronic System Division Technical Report No. $66-350)$.

21 Lampson, Butler W. "A critique of "An exploratory investigation of programmer performance under on-line and off-line conditions." "IEEE Trans. Human Factors in Electronics $>$, pp. 48-51.

22 Meyer, T. H. and I. E. Sutherland. "On the design of display processors." 〈Comm. ACM〉, 11:6 (June, 1968), pp. $410-414$.

23 Miller, Robert B. "Response time in man-computer conversational transactions." 〈Proc.〉 Fall Joint Computer Conference, 1968, pp. 267-277.

24 Nelson, E. A. "Management handbook for the estimation of comouter programming costs." System Development Corporation, Technical Memorandum No. 3225, March 20, 1967.

25 Poole, Harry H. "Computer display system tradeof's." In <Computer Graphics: Techniques and Applications>, Eds.: Parslow, Prowse \& Green. New York: Plenum Press, 1969.

26 Prince, M. David. LInteractive Graphics for Computer-Aided Design>. Reading, Massachusetts: Addison-Wesley, 1971.

27 Sackman, Harold. 〈Man-Computer Problem Solving>. Princeton, N. J.: Auerbach Publishers Inc., 1970.

28 Sackman, Harold. <Mass Information Utilities and Social Excellence>. Princeton, N. J.: Auerbach Publishers, 1972.

29 Schatzoff, M., Tsao, R. and R. Wiig. "An experimental comparison of time sharing and batch processing." 〈CACM〉, May 1967, pp. 261-55.

30 Smith, J. Meredith. "A review and comparison of certain methods of computer performance evaluation." <Computer Bulletin>, 12:1 (May 1868), pp. 13-18. 
31 Thomas, E. M. "System considerations for graphic data processing." 〈Computers and Automation>, November, 1967 , pp. 16-19.

32 Ward, John E. "Systems engineering problems in computer-driven CRT displays for man-machine communication." 〈IEEE Trans. System Science and Cybernetics>, 3:1 (June $1967), p p .47-54$.

33 Yule, A. "Human response time in a graphic environment." <Computer Bull.>, June 1972, pp. 304-305. 

NBS.IIAA IREV.7-73)

U.S. DEPT. OF COMM

BIBLIOGRAPHIC DATA SHEET

1. PUBL.IS ATION OR REPORT NO.

2. Gov't Accession

NBS TN -826

4. TITLE AND SUBTITLE

Cost-Benefit Analysis of Computer Graphics Systems

5. Publication Date

April 1974

6. Performing Organization Code

8. Performing Organ. Report No.

Ira W. Cotton

10. Project/Task/Work Unit No. 6505373

NATIONAL BUREAU OF STANDARDS

DEPARTMENT OF COMMERCE

WASHINGTON, D.C. 20234

11. Contract/Grant No.

73-90042

12. Sponsoring Organization Name and Complete Address (Street, City, State, ZIP)

U. S. Army Electronics Command

AMSEL-GG-OD

Fort Monmouth, N. J. 07703

13. Type of Report \& Period Covered

Fina 1 7/72-6/73

14. Sponsoring Agency Code

\section{SUPPLEMENTARY NOTES}

16. ABSTRACT (A 200-word or less factual summary of most significant information. If document includes a significant bibliography or literature survey, mention it here.)

This report assesses the state-of-the-art in cost benefit analyses of computer graphics systems and suggests an approach for developing improved methodology. Cost-benefit analyses are distinguished from analyses of system performance in that the latter are directed at optimizing system performance at a given level of investment, while the former are directed at justifying the investment itself.

Computer graphic system design alternatives are first outlined. Then methods of analyzing the performance and costs of computer systems in general and graphic systems in particular are discussed. With this information it is shown how cost-effectiveness analyses may be performed. The next crucial step is to conduct benefit analysis, an ill-defined art. The results of benefit analysis must be combined with cost-effectiveness analysis in order to perform the desired cost-benefit analysis.

An experimental methodology is suggested for better performing benefit analyses of computer graphic systems. A more rigorous formulation of the cost-benefit procedure is then outlined. No attempt is made in this report to actually perform such an analysis.

17. KEY WORDS (six to twelve entries; alphabetical order; capitalize only the first letter of the first key word unless a proper name; separated by semicolons)

Computer graphics; cost-benefit analysis; cost-effectiveness; economics; performance evaluation
18. AVAILABILITY
X Unlimited

For Official Distribution. Do Not Release to NTIS

— Order From Sup. of Doc., U.S. Government Printing Office Washington, D.C. 20402, SD Cat. No.C13.46:826

19. SECURITY CLASS (THIS REPURT)

UNCL ASSIF IE D

20. SECURITY CLASS (THIS PAGE)

UNCLASSIFIED
21. NO. OF PAGES

22. Price

90 cents 



\section{NBS TECHNICAL PUBLICATIONS}

PERIODICALS

JOURNAL OF RESEARCH reports National Burcau of Standards research and development in phrsics, mathematics, and chemistry. Comprehensive scientific papers give complete details of the work, including laboratory data, experimental proccdures, and theoretical and mathematical analyses. Illustrated with photographs, drawings, and charts. Includes listings of other NBS papers as issued.

Published in two sections, available separately:

\section{- Physics and Chemistry (Section A)}

Papers of interest primarily to scientists working in these fields. This section covers a broad range of physical and chemical research, with major emphasis on standards of physical measurement, fundamental constants, and properties of matter. Issued six times a vear. Annual subscription: Domestic, $\$ 17.00$; Foreign. \$21.25.

\section{- Mathematical Sciences (Section B)}

Studies and compilations designed mainly for the mathematician and theoretical physicist. Topics in mathematical statistics, theory of experiment design, numerical analysis, theoretical physics and chemistry, logical design and programming of computers and computer systems. Short numerical tables. Issued quarterly. Annual subscription: Domestic, $\$ 9.00$; Foreign, $\$ 11.25$.

\section{DIMENSIONS, NBS}

The best single source of information concerning the Bureau's measurement, research, developmental, cooperative, and publication activities, this monthly publication is designed for the layman and also for the industry-oriented individual whose daily work involves intimate contact with science and technology - for engineers, chemists, physicists, research managers, product-development managers, and company executives. Annual subscription: Domestic, $\$ 6.50$; Foreign, $\$ 8.25$

\section{NONPERIODICALS}

Applied Mathematics Series. Mathematical tables, manuals, and studies.

Building Science Series. Research results, test methods, and performance criteria of building materials, components, systems, and structures.

Handbooks. Recommended codes of engineering and industrial practice (including safety codes) developed in cooperation with interested industries, professional organizations, and regulatory bodies.

Special Publications. Proceedings of NBS conferences, bibliographies, annual reports, wall charts, pamphlets, etc.

Monographs. Major contributions to the technical literature on various subjects related to the Bureau's scientific and technical activities.

National Standard Reference Data Series. NSRDS provides quantitative data on the physical and chemical propcrties of materials, compiled from the world's literature and critically evaluated.

Product Standards. Provide requirements for sizes, types, quality, and methods for testing various industrial products. These standards are developed cooperatively with intercsted Government and industry groups and provide the basis for common understanding of product characteristics for both buyers and sellers. Their use is voluntary.

Technical Notes. This series consists of communications and reports (covering both other-agency and NBS-sponsored work) of limited or transitory interest.

Federal Information Processing Standards Publications. This series is the official publication within the Federal Government for information on standards adopted and promulgated under the Public Law 89-306, and Bureau of the Budget Circular A-86 entitled, Standardization of Data Elements and Codes in Data Systems.

Consumer Information Series. Practical information. based on NBS research and experience, covering areas of interest to the consumer. Easily understandable language and illustrations provide useful background knowledge for shopping in today's technological marketplare.

\section{BIBLIOGRAPHIC SUBSCRIPTION SERVICES}

The following current-awareness and literature-survey bibliographies are issued periodically by the Bureau:

Cryogenic Data Center Current Awareness Service (Publications and Reports of Interest in Cryogenics). A literature survey issued weekly. Annual subscription : Domestic, $\$ 20.00$; foreign, $\$ 25.00$.

Liquefied Natural Gas. A literature survey issued quarterly. Annual subscription: $\$ 20.00$.

Superconducting Devices and Materials. A literature survey issued quarterly. Annual subscription: $\$ 20.00$. Send subscription orders and remittances for the preceding bibliographic services to the U.S. Department of Commerce, National Technical Information Service, Springfield, Va. 22151.

Electromagnetic Metrology Current Awareness Service (Abstracts of Selected Articles on Measurement Techniques and Standards of Electromagnetic Quantities from D-C. to Millimeter-Wave Frequencies). Issued monthly. Annual subscription: $\$ 100.00$ (Special rates for multi-subscriptions). Send subscription order and remittance to the Electromagnetic Metrology Information Center, Electronagnetics Division, National Bureau of Standards, Boulder, Colo. 80302.

Order NBS publications (except Bibliographic Subscription Services) from: Superintendent of Documents, Government Printing Office, Washington, D.C. 20402. 
U.S. DEPARTMENT OF COMMERCE

National Bureau of Standards

Washington, D.C. 20234

POSTAGE AND FEES PAID U.S. DEPARTMENT OF COMMERCE

OFFICIAL BUSINESS

COM-215

Penalty for Private Use, $\$ 300$ 